\title{
A diagnostic marker for speech delay associated with otitis media with effusion: the intelligibility-speech gap
}

\author{
LAWRENCE D. SHRIBERG $\dagger$, \\ PETER FLIPSEN JR. $\$$, JOAN KWIATKOWSKI $\dagger$ \\ and JANE L. MCSWEENY $\dagger$ \\ $\dagger$ University of Wisconsin-Madison, WI, USA \\ $\$$ University of Tennessee-Knoxville, TN, USA
}

(Received 26 July 2002; accepted 19 September 2002)

\begin{abstract}
The goal of this study was to determine if notably reduced intelligibility is a potential diagnostic marker for children with speech delay and histories of early recurrent otitis media with effusion (SD-OME). Intelligibility was assessed in one 5-10 minute conversational speech sample from each of 281 speakers. The OME histories of 148 of these children with normal speech acquisition were described in two prior reports. OME histories of 85 additional children with speech delay were obtained from case history reports. For both groups, the children with positive OME (OME +) histories had significantly lower intelligibility scores but significantly higher speech production scores than children with negative OME (OME-) histories. Findings for a diagnostic marker to discriminate speech delayed children with OME + versus OMEhistories were promising, considering that the data were obtained retrospectively and did not include audiological information characterizing children's concurrent fluctuant hearing loss. The formula for the diagnostic marker, termed the Intelligibility-Speech Gap, was identified by a machine learning routine. Diagnostic accuracy findings for the marker were as follows: positive predictive value $=74 \%$, negative predictive value $=86 \%$, sensitivity $=79 \%$, specificity $=83 \%$, positive likelihood ratio $=4.6$ and negative likelihood ratio $=0.25$. Discussion considers speech processing perspectives on the source of the intelligibilityspeech gap in children with suspected SD-OME, and methodological perspectives on its development as a diagnostic marker of one etiological subtype of speech delay.
\end{abstract}

Keywords: Articulation, classification, hearing, phonology, speech disorder.

Address correspondence to: Lawrence D. Shriberg, Phonology Project, Waisman Center, University of Wisconsin-Madison, 1500 Highland Avenue, Madison, WI 53705, USA. e-mail: shriberg@waisman.wisc.edu; website: http://www.waisman/wisc.edu/phonology/index.htm 


\section{Introduction}

\section{Research perspectives in otitis media with effusion and speech delay}

The hypothesis proposed in the present and in a companion study (Shriberg, Kent, Karlsson, McSweeny, Nadler and Brown, 2003) is that there is an etiological subtype of speech disorder consequent to the fluctuant hearing loss that may be present in one or both ears during episodes of otitis media with effusion. Elsewhere, the working term used to differentiate this proposed subtype of speech delay $(S D)$ from other putative etiological subtypes of SD is Speech Delay-Otitis Media with Effusion (SD-OME) (Shriberg, Austin, Lewis, McSweeny and Wilson, 1997b; Shriberg, Flipsen, Thielke, Kwiatkowski, Kertoy, Katcher, Nellis and Block, 2000). The large body of research in SD-OME can be divided into three classes of research designs or paradigms, as described in the following brief summaries providing background and findings.

\section{Risk factor studies}

The most widely reported programmatic research on OME and speech is based on the research paradigm of SD as a disorder with significant implications for public health. An initial question is whether SD is of itself (i.e. without comorbid language impairment) a significant public health issue. Since the 1920s, the effects of speechsound disorders on a child's educational achievement, psychosocial adjustment and eventual vocational choices have been well documented. This research history includes findings associating SD with increased risk for (a) negative self-concept (1920s-1960s), (b) unsuccessful discourse (1970s-1980s) and (c) a clinical or subclinical problem in reading and other verbal skills (1990s-present). In the first research period, a number of classic studies documented that persistent misarticulation of even one frequently occurring phoneme could have significant negative impact on a speaker's self-concept and could also have lasting social and vocational consequences (more recently, see Silverman and Paulus, 1989; Felsenfeld, Broen and McGue, 1992). In the second research period, the significance of child speech-sound disorders shifted to discourse issues, focusing on the consequences of unintelligible speech for pragmatic needs in language acquisition. In the 1990s, the social emphasis of both prior research periods shifted to concern that phonological processing deficits placed a child at risk for reading, spelling and learning disability and issues in other areas of verbal learning (e.g. Bird, Bishop and Freeman, 1995). Concerns from each of these three historic perspectives continue to be valid for persons with this highly prevalent (estimated at 3.8\%; Shriberg, Tomblin and McSweeny, 1999) childhood disorder.

Epidemiologic methods are used to estimate if recurrent OME is a risk factor for $\mathrm{SD}$, with statistical indices such as relative risk and odds ratios expressing the degree of risk. A hallmark of the epidemiologic approach is the use of one metric to index the target disorder, although a few readily administered nominal or continuous measures are often used. In studies of SD, for example, epidemiologic needs are for an efficient measure both to indicate whether speech is delayed or impaired at certain clinically relevant age levels and to provide a global index of severity of involvement. Given these measurement constraints, robust estimates of 
risk from large numbers of tested participants require a well developed rationale for the selection of typically just one index of disorder.

From a box-score, meta-analytic perspective, findings for OME as a risk factor for SD are equivocal. Shriberg, Flipsen et al. (2000) reviewed 27 published studies, from the benchmark Holm and Kunze (1969) paper to articles published in approximately 1997, that studied whether OME before age 2 placed a child at increased risk for SD at ages 5 to 9 years. These authors concluded that support for a correlative association between early OME and concurrent or later SD was equivocal and support for a causal association remained undocumented. A total of 17 studies $(63 \%)$ failed to reject a null hypothesis of no statistically significant difference on one or more of the speech indices assessed. However, 21 of the studies (78\%) yielded a statistically significant finding associating OME with deficits in one or more metrics of speech status.

Since 1997, a number of studies have continued to provide only equivocal support for OME as a risk factor for later SD. Studies reporting that OME poses increased risk for delays in speech-language or other verbal trait variables (e.g. reading) — most with modest and/or transient effect sizes-include Bennett and Haggard (1999); Lindsay, Tomazic, Whitman and Accardo (1999); Maw, Wilks, Harvey, Peters and Golding (1999); Kindig and Richards (2000); Klausen, Møller, Holmefjord, Reisæter and Asbjørnsen (2000); Rosenfeld, Bhaya, Bower, Brookhouser, Casselbrant, Chan, Cunningham, Derkay, Gray, Manning, Messner and Smith (2000); Shriberg, Flipsen et al. (2000); and Shriberg, Friel-Patti, Flipsen and Brown (2000). Studies that have reported negative findings for OME as a risk factor for speech-language acquisition include those based on the large cohorts of children followed by the Pittsburgh group (Feldman, Dollaghan, Campbell, Colborn, KursLasky, Janosky and Paradise, 1999; Paradise, Dollaghan, Campbell, Feldman, Bernard, Colborn, Rockette, Janosky, Pitcairn, Sabo, Kurs-Lasky and Smith, 2000; Paradise, Feldman, Campbell, Dollaghan, Colborn, Bernard, Rockette, Janosky, Pitcairn, Sabo, Kurs-Lasky and Smith, 2001) and the Chapel Hill group (Roberts, Burchinal, Zeisel, Neebe, Hooper, Roush, Bryant, Mundy and Henderson, 1998; Roberts, Burchinal, Jackson, Hooper, Roush, Mundy, Neebe and Zeisel, 2000). A recent meta-analysis limited to the possible language sequelae of OME concluded, 'the results of the more recent prospective studies may be viewed as less conclusive and more equivocal' (Casby, 2001). Thus, trends from these latter prospective samples suggest increased caution about the speech-language sequelae that influence treatment options for children with early recurrent OME. A clear trend in this literature throughout the past three decades is the need for multifactorial pathway models, including variables such as level of education of the mother and other demographic variables as major sources of variance associated with speechlanguage and other outcomes. To date, the most recent comprehensive reviews of studies in OME and its sequelae may be found in proceedings from a consensus conference (Roberts and Hunter, 2002).

\section{Descriptive-linguistic studies}

A second type of research paradigm that has been used in OME-speech research differs markedly in goals and methods from the epidemiological, risk factor approach. A number of investigators have used case-study, cross-sectional and longitudinal designs to provide intensive linguistic descriptions of the speech 
characteristics of infants, toddlers and pre-school children with histories of significant OME and fluctuant hearing loss. A hallmark of these descriptive studies is their focus on the interpretation of findings from various linguistic and psycholinguistic perspectives to propose explanatory accounts of possible speech processing variables that link the hearing loss associated with OME with data on comprehension and production phonology.

Of particular interest in the present context are the positive findings from a number of studies that have provided detailed data on the emergence of speech in very young children sampled repeatedly during and following documented episodes of OME and hearing loss. Recent examples include studies by research groups in New York City (e.g. Mody and Schwartz, 1999; Petinou, Schwartz, Mody and Gravel, 1999; Petinou, Schwartz, Gravel and Raphael, 2001), State College, PA (e.g. Miccio, Yont, Davie and Vernon-Feagans, 1999; Miccio, Gallagher, Grossman, Yont and Vernon-Feagans, 2001) and Calgary-Montreal (e.g. Rvachew, Slawinski, Williams and Green, 1996a; 1996b; Rvachew, Slawinski, Williams and Green, 1999). A consistent finding across these studies is that there are reliable qualitative and quantitative differences in the topography of babbling and early word forms of children with positive OME histories compared to controls. Causal pathway models relate the consequences of fluctuant hearing loss to speech differences using a number of phonological (e.g. feature geometry) and psycholinguistic (e.g. phonetic encoding, phonological working memory) constructs. The general issue is that unlike the risk for speech delay associated with cognitive or articulatory deficits, the risk for speech delay from OME is based on the perceptually centred risk to the establishment of stable underlying phonological representations-elements of language acquisition that provide the central scaffold for all verbal learning.

\section{Diagnostic marker studies}

A third paradigm in OME-speech research has sought to identify diagnostic markers for children whose speech delay or risk for speech delay is associated with the type and degree of hearing loss consistent with early recurrent OME. The goals and methods of this paradigm differ substantially from those just described for risk factor and descriptive linguistic studies. Diagnostic markers are measurable characteristics used to classify persons as affected for a target disorder. Although validated markers may provide information that is useful in explicating the nature of a disorder, their primary purpose is as a measurement tool for diagnostic classification.

Several quantitative metrics are commonly used to assess the utility of a proposed diagnostic marker for a disorder or disease. Each index requires the availability of one or more 'gold standards' against which the validity of the proposed marker can be evaluated. Ideal diagnostic markers have maximum positive predictive value (persons predicted to have the disorder are or become positive for the disorder) and maximum negative predictive value (persons predicted not to have the disorder are and remain negative for the disorder). Ideal diagnostic markers also have maximum sensitivity (detect all affected cases) and maximum specificity (reject all unaffected cases). Finally, ideal diagnostic markers also have high positive likelihood ratios $(L R)$ and low negative likelihood ratios. A likelihood ratio 'expresses the odds that a given level of a diagnostic test result would be expected in a patient with (as opposed to one without) the target disorder' (Sackett, 
Haynes, Guyatt and Tugwell, 1991). For example, a positive LR of 5.5 would indicate that a score at or above the positive range for the marker is 5.5 times as likely to come from a person who has the disorder as from a person who does not have the disorder. In contrast, a negative LR of 0.20 would indicate that a score below the positive range (i.e. a negative test result) is less than two-tenths as likely to come from a person with the disorder as from a person without the disorder. In general, the more rare the target disorder, the wider its range of severity of expression, and the greater its similarity to other disorders in a classification system, the more difficult the task to identify, develop and validate markers with acceptable levels of diagnostic accuracy.

An historical review of one group's attempt to identify diagnostic markers for SD-OME is provided in Shriberg et al. (2003). Essentially, several types of sound changes have been observed to be notably more frequent in children with speech delay and positive histories for OME. The current focus is on one of those observations, described most recently in two reports using risk factor designs to assess causal and predictive relationships between both speech delay and OME (Shriberg, Flipsen et al., 2000), and speech delay and hearing loss associated with OME (Shriberg, Friel-Patti et al., 2000). The observation is that, relative to children with SD and negative OME histories, the intelligibility of children with SD and positive OME histories seems to be notably poorer. The present report describes empirical findings for this potential diagnostic marker of SD-OME. Before proceeding to the study, it is useful to consider two alternative theoretical perspectives on reasons why the speech of children with early frequent OME might be particularly unintelligible.

\section{Alternative explanatory accounts of SD-OME}

\section{Acoustic-phonetic account}

One explanation for the reduced intelligibility observed in children with suspected SD-OME posits specific deficits in these children's representations of the subphonemic features of their ambient language. This acoustic-phonetic account is consistent with the explanatory framework proposed in Shriberg and Smith (1983) and amplified in Shriberg (1987). The explanation for the sound changes observed in word-initial consonants and nasals (in singletons or cluster contexts) was that they were underspecified in children's underlying representations due to their reduced perceptual salience. Thus, the acoustic-phonetic perspective claims that reduced intelligibility in children with SD-OME is a consequence of these children's failure to discriminate, store and reproduce the many subtle acoustic contrasts necessary for the listener to track meaning. The perceptual deficits in this causal chain are the fluctuant and degraded auditory signals presented to the cochlea during a significant number of lengthy episodes of OME.

\section{Mediated account}

An alternative account for the locus of observed reduced intelligibility in children with suspected SD-OME, the mediated account, is that the fluctuant hearing loss in OME engenders diffuse cognitive-linguistic effects, affecting in turn speech perception and speech production. For example, deletions of $/ \mathbf{h} /$ in unstressed monosyllabic pronouns (e.g. him, his, her) could occur as the direct consequence of failure to correctly represent the initial consonant in these words (as posited in the 
direct account above). Alternatively, such deficits in children with SD-OME could be due to complex interactions affecting language acquisition, in this case acquisition of the pronoun system (as posited in the mediated account). Although the acoustic-phonetic account of the intelligibility deficit associated with SD-OME is more consistent with the possibility of identifying a diagnostic marker than the mediated account, several considerations support the theoretical coherence of the mediated account.

\section{Support for a mediated effects account}

One observation that supports a mediated account of intelligibility deficits in SD-OME is the diversity of speech error profiles reported for persons with sensorineural hearing impairments (e.g. Levitt and Stromberg, 1983; Osberger, 1992; Stoel-Gammon and Kehoe, 1994). Persons with similar types and degrees of hearing loss may have large individual differences in their speech production, as assessed using perceptual and instrumental methods. Crucially, there does not appear to be a set of diagnostic markers with the requisite sensitivity and specificity to discriminate speech disorder associated with mild hearing loss from other forms of speech disorder. Significant individual differences in the speech patterns of persons with relatively stable hearing loss would seem to support the validity of mediated rather than direct acoustic-phonetic effects explanatory models.

A second observation in support of a mediated account concerns research in a topic termed clear speech (e.g. Picheny, Durlach and Braida, 1986; 1989; Krause and Braida, 1995; Howell and Bonnett, 1997). Reports in this literature indicate that typical speakers readily learn how to adjust their speech to become more intelligible and that these adjustments are reflected in acoustic properties of speech. These pragmatically driven adjustments in the service of intelligibility involve tradeoffs at subphonemic and suprasegmental levels. Constraints on the deployment of such adjustments by children with histories of OME are conceptually less consistent with an acoustic-phonetic account of the intelligibility deficit, but quite consistent with a mediated, constructivist perspective. This latter account would predict that children with $\mathrm{OME}+$ histories would be significantly less active in monitoring for intelligibility (Shriberg and Kwiatkowski, 1990). Shriberg (1987) and Paul (1995) have discussed the construct of tuning in and tuning up to capture the two-step process that presumably must occur for speakers to achieve and maintain intelligible speech.

Finally, in support of a mediated account, recent structural equation findings in Shriberg, Friel-Patti et al. (2000) indicated that the effects of early fluctuant hearing loss on later speech status were significantly and substantially mediated by a child's concurrent language status. As reviewed previously, such findings supporting a multifactorial risk model for speech delay appear to be among the most often discussed conclusions of the many recent large-scale epidemiologic studies. Thus, the preponderance of research findings would argue against the perspective that essentially autonomous, acoustic-phonetic deficits in the speech signal underlie the intelligibility deficits observed in children with histories of $\mathrm{OME}+$. This issue will be examined in the discussion of the present findings. 


\section{Statement of purpose}

The goal of the present study was to determine if samples of children with SDOME have lower average intelligibility than samples of children with other forms of speech delay, and if so, whether intelligibility itself (or a metric derived from intelligibility) might meet customary criteria for a diagnostic marker of SD-OME. As in other studies of child speech-sound disorders of currently unknown origin, the design included auditory-perceptual data reduction methods that were sensitive to both clinical and subclinical speech errors and differences (cf. Shriberg, 1993, Appendix).

\section{Method \\ Participants}

To maximize the generalizability of findings, the study was designed to use the type of OME information that is typically available in clinical intake questionnaires and

Table 1. Gender and age characteristics for Studies 1-4, including information on the severity subgroups

\begin{tabular}{|c|c|c|c|c|c|c|c|c|c|}
\hline & \multicolumn{3}{|c|}{ Total Group } & \multicolumn{3}{|c|}{ OME Severity Subgroup } & \multicolumn{3}{|c|}{ Speech Severity Subgroup } \\
\hline & $\mathrm{OME}+$ & OME- & $p$ & $\mathrm{OME}+$ & OME- & $p$ & $\mathrm{OME}+$ & OME- & $p$ \\
\hline \multirow{2}{*}{\multicolumn{10}{|c|}{ Sample 1}} \\
\hline$n$ & & & & & & & & & \\
\hline Boys & 20 & 36 & \multirow[t]{3}{*}{$<0.49^{\mathrm{a}}$} & - & - & \multirow[t]{3}{*}{ - } & 9 & 17 & \multirow[t]{3}{*}{$<0.72^{\mathrm{a}}$} \\
\hline Girls & 13 & 16 & & - & - & & 3 & 10 & \\
\hline Total & 33 & 52 & & - & - & & 12 & 27 & \\
\hline \multicolumn{10}{|c|}{ Age (months) } \\
\hline$M$ & 49.5 & 52.3 & \multirow{2}{*}{$<0.12^{\mathrm{b}}$} & - & - & \multirow[t]{2}{*}{ - } & 48.2 & 51.2 & \multirow[t]{2}{*}{$<0.28^{\mathrm{b}}$} \\
\hline$S D$ & 7.8 & 8.5 & & - & - & & 7.6 & 9.0 & \\
\hline \multicolumn{10}{|l|}{ Sample 2} \\
\hline Boys & 10 & 8 & \multirow[t]{3}{*}{$<1.00^{\mathrm{a}}$} & 2 & 5 & \multirow[t]{3}{*}{$<0.34^{\mathrm{a}}$} & - & - & \multirow[t]{3}{*}{ - } \\
\hline Girls & 9 & 8 & & 7 & 4 & & - & - & \\
\hline Total & 19 & 16 & & 9 & 9 & & - & - & \\
\hline \multicolumn{10}{|c|}{ Age (months) } \\
\hline$M$ & 43.7 & 43.6 & \multirow[t]{2}{*}{$<0.93^{\mathrm{b}}$} & 43.6 & 42.9 & \multirow[t]{2}{*}{$<0.73^{\mathrm{b}}$} & - & - & \multirow[t]{2}{*}{-} \\
\hline$S D$ & 3.6 & 3.7 & & 3.9 & 4.3 & & - & - & \\
\hline \multicolumn{10}{|l|}{$\underset{n}{\text { Sample }} 3$} \\
\hline Boys & 9 & 16 & \multirow[t]{3}{*}{$<1.00^{\mathrm{a}}$} & 8 & 8 & \multirow[t]{3}{*}{$<1.00^{\mathrm{a}}$} & 7 & 5 & \multirow[t]{3}{*}{$<1.00^{\mathrm{a}}$} \\
\hline Girls & 10 & 15 & & 6 & 6 & & 6 & 4 & \\
\hline Total & 19 & 31 & & 14 & 14 & & 13 & 9 & \\
\hline \multicolumn{10}{|c|}{ Age (months) } \\
\hline$M$ & 55.8 & 57.5 & \multirow[t]{2}{*}{$<0.43^{\mathrm{b}}$} & 56.5 & 57.6 & \multirow[t]{2}{*}{$<0.69^{\mathrm{b}}$} & 56.9 & 58.1 & \multirow[t]{2}{*}{$<0.70^{\mathrm{b}}$} \\
\hline$S D$ & 7.2 & 7.2 & & 7.2 & 7.0 & & 7.6 & 7.4 & \\
\hline \multicolumn{10}{|l|}{ Sample $4^{\mathrm{c}}$} \\
\hline Boys & 7 & 19 & \multirow[t]{3}{*}{$<0.77^{\mathrm{a}}$} & 7 & 6 & \multirow[t]{3}{*}{$<0.43^{\mathrm{a}}$} & 3 & 16 & $<0.32^{\mathrm{a}}$ \\
\hline Girls & 8 & 29 & & 8 & 3 & & 9 & 20 & \\
\hline Total & 15 & 48 & & 15 & 9 & & 12 & 36 & \\
\hline
\end{tabular}

Note: Dashes indicate that there was no OME severity subgroup or no Speech severity subgroup for the study sample.

${ }^{a}$ Fisher exact tests; ${ }^{b}$ two-sample $t$ tests; ${ }^{c}$ all participants were 36 months of age. 
assessment data. The following paragraphs describe the four cohorts of children (Samples 1-4) with typical and atypical speech development whose conversational speech samples and associated clinical records comprised the data of this study. Summary descriptive data for the four participant samples are provided in table 1.

\section{Sample 1: children with delayed speech}

A database of children who had been treated and/or assessed at the University of Wisconsin-Madison Phonology Clinic was searched to identify children whose case history and intervention histories included ample documentation of significant OME. Case records information was available for 25 variables that chronicled children's OME histories, including otolaryngologic, audiologic and tympanometric information on frequency, type and severity of OME episodes, history of insertion of pressure equalization tubes, and questionnaire data on caregivers' observations about their children's hearing (cf. Shriberg and Kwiatkowski, 1994).

From a total of 212 children for whom standard conversational speech samples had been obtained, 33 children were identified who had significant histories of $\mathrm{OME}(\mathrm{OME}+)$. Episodes of middle ear involvement occurred early and frequently in each child, with many children receiving pressure equalization tubes after antimicrobial regimens failed to resolve recurrent OME. A total of 52 children with speech delay who were in the same age range and gender distribution were selected as controls (OME-). The inclusionary criterion for this group was a history indicating zero to no more than three episodes of OME by the age at which the conversational speech sample was obtained. As the goal was to examine the data for evidence of a diagnostic marker for SD-OME, there was no attempt to control for any other individual difference variable other than age and gender in the case history information.

Samples 2-4: children with typically developing speech

Data from three other samples of children whose OME histories were well documented were also assembled for the goals of the present study. All children were free of major physical, cognitive or psychosocial involvements. Complete descriptions of ascertainment and subject characteristics are available in the reference cited for each study sample.

Sample 2 was a cohort of 35 children whose health had been followed since birth in a university paediatrics clinic. Using criteria for the 36-month OME histories described in Shriberg, Flipsen et al. (2000), 19 children were selected for an OME + subgroup (6 weeks or more of involvement by 3 years of age), and 16 children were selected for an OME - subgroup ( $0-6$ weeks of involvement by 3 years of age).

Sample 3 was a group of 50 Native American children whose health had been followed since infancy in their tribal health clinic. Using the OME history criteria described in Shriberg, Flipsen et al. (2000), 19 children were classified as OME+ (6-23 medical treatments), and 31 children were classified as OME - (0-1 medical treatments).

Sample 4 was a subsample of 63 infants whose health and hearing status had been followed since 2 months of age in a private paediatrics practice participating in a study of otitis media and language (Friel-Patti and Finitzo, 1990). Using audiological criteria developed in the original study and described in Shriberg, Friel-Patti et al. (2000), children were divided into OME + and OME - subgroups 
based on average hearing levels higher or lower than $20 \mathrm{~dB}$ HL, respectively, at 12-18 months. Average hearing levels were also available for children from 6 to 12 months. However, the present study used the 12-18 month average hearing levels because findings indicated that hearing levels in this later period were more associated with speech development at 3 years of age (Shriberg, Friel-Patti et al., 2000). A total of 15 children had greater than $20 \mathrm{~dB}$ average hearing levels $(\mathrm{OME}+)$ from 12 to 18 months and 48 children had $20 \mathrm{~dB}$ or lower average hearing levels $(\mathrm{OME}-)$ during this period.

\section{OME severity subgroups}

As suggested previously, ideal diagnostic markers are sensitive to the full range of a disorder's severity of expression. To assess the possibility that intelligibility as a marker was sensitive to only the most severe OME involvement (a proxy for frequently poorer hearing levels), subsamples termed OME severity subgroups were assembled for three of the four study samples. OME severity subgroups were not assembled for Sample 1, because in comparison to the systematic medical records in the other three study samples, the records in the database were considered insufficient for this subanalysis. In Sample 2, nine children with at least 18 weeks of medically confirmed OME involvement (range $=18-58$ weeks, $\mathrm{M}=26.4, \mathrm{SD}=12.8$ ) comprised the OME + severity subgroup (see table 1), and nine children with $0-2$ weeks of involvement $(\mathrm{M}=1.1, \mathrm{SD}=1.1)$ comprised the $\mathrm{OME}-$ comparison subgroup. For Sample 3, the two OME severity subgroups were assembled from a subset of 28 children with the most detailed medical records. The number of medical treatments for middle ear disease for the 14 children in the OME+ subgroup ranged from six to 23 , with the remaining 14 children in the OMEsubgroup having 0-1 medical treatments. Hearing level criteria were used to assemble OME severity subgroups for Sample 4, because hearing levels from 6 to 18 months were available, and prior findings indicated that hearing levels were more strongly associated with later speech-language status than with episodes of OME (Shriberg, Friel-Patti et al., 2000). Average hearing levels from 12 to 18 months were inspected for appropriate cut-off values, relative to the $20 \mathrm{~dB} \mathrm{HL}$ criterion dividing $\mathrm{HL}+$ from $\mathrm{HL}-$ in the total group comparisons. A total of 15 children, whose average hearing levels from the age of 12-18 months were equal to or greater than $20 \mathrm{~dB} \mathrm{HL}$, were designated as the $\mathrm{OME}+$ severity subgroup, and nine children whose average hearing levels were less than $10 \mathrm{~dB}$ HL during this period were designated as the OME- severity subgroup.

Table 1 provides information on the number and gender of children in the four samples, including descriptive and inferential statistics for the OME severity subgroups and for the speech severity subgroups (to be described). All children were within the normal range in cognitive development. Fisher exact and twosample $t$ tests indicated that there were no statistically significant differences in the gender or ages of children in any of the total group or subgroup comparisons.

\section{Speech assessment}

Assessment and transcription

Conversational speech samples for each child in samples 1-3 had been obtained following procedures described in Shriberg and Kwiatkowski (1980). Sony 5000 
audiocassette recorders, matching external microphones and high-quality analogue audiocassette tapes were used, with mouth-to-microphone distance monitored at approximately $15 \mathrm{~cm}$. The conversational samples for Sample 4 were obtained following the guidelines recommended for free speech sampling in Miller and Chapman (1986). Two experienced transcribers used Dictaphone Model 2550 play back devices to transcribe the speech samples, using a system of narrow phonetic transcription (Shriberg and Kent, 1995) and conventions developed for research in child phonology. Transcribers were permitted at least three repetitions of a string of speech to attempt to gloss what the child had intended to say and were aided by the glossing and comments recorded online by the examiner. The transcriber may or may not have agreed with the examiner's gloss. A set of asterisk conventions was used to indicate syllables and words that remained unintelligible after three or more replays. The resulting transcripts were formatted for computer analysis using enhancements to the PEPPER suite (Shriberg, Allen, McSweeny and Wilson, 2001).

Point-by-point percentages of agreement data for the transcribers in these four study samples have been reported in detail in the reference citations and in a prior report on the reliability of broad and narrow phonetic transcription of consonants and vowels/diphthongs (McSweeny and Shriberg, 1995). For a representative sample of 32 conversational speech samples, interjudge percentage of agreement for consonant transcription was approximately $90 \%-95 \%$ (broad transcription) and $74 \%-85 \%$ (narrow transcription); for vowels/diphthongs, the range was approximately $86 \%-97 \%$ (broad transcription) and $71 \%-85 \%$ (narrow transcription). The standard error of measurement estimates for the nine speech measures used in this study averaged 1-3 percentage points for the total scores and 3-6 percentage points for developmental sound class subscales (Shriberg, Austin, Lewis, McSweeny and Wilson, 1997a, table 3).

\section{Severity of speech involvement}

For all of the 233 conversational speech samples in the four studies, software provided scores for each of the 10 measures of articulatory competence described in Shriberg et al. (1997a). Rationale for the use of this suite of metrics in etiological and epidemiological research, in comparison to other available measures such as data from citation-form articulation tests, has been discussed elsewhere (e.g. Shriberg, 1993; Shriberg et al., 1997a, b). Nine of the 10 speech metrics treat articulatory competence as a criterion-referenced continuous trait, with $100 \%$ on a metric reflecting maximum articulatory competence. The Intelligibility Index, the primary speech variable in the current study, is a percentage reflecting the proportion of words a transcriber is able to gloss from an audiocassette recording of a child's conversational speech with an examiner. As reviewed elsewhere, the Intelligibility Index percentages provided by this metric are deliberately maximized. That is, glosses are provided both by a professionally trained examiner and by a research transcriber, and the transcriber is allowed multiple repetitions to attempt to recover the child's intended word targets (Shriberg et al., 2001).

\section{Speech severity subgroups}

To assess the possibility of a diagnostic marker for SD-OME sensitive only to severely speech-involved children, several speech severity subsamples were assembled for each of the four study samples. 
Because all children in Sample 1 were speech disordered, a conservative $z$ score for the Percentage of Consonants Correct-Revised (PCC-R) metric (cf. Shriberg et al., 1997b) was used to assemble a speech severity subgroup for this study sample. To be included in the Sample 1 Speech severity subgroup, a child was required to have a $z$ PCC-R score of 5 or more standard deviation units below the mean PCC-R score of typically speaking children of the same age and gender (Shriberg et al., 1997a). A total of 12 children in the OME + subgroup and 27 children in the OME- subgroup met this criterion for severe speech involvement. The mean ages of children in the two Speech severity subgroups were not significantly different from those of the speech-disordered children in the OME + and OME- subgroups $(t(25)=1.09, p=0.28)$.

In Samples 2-4, in which the children were not ascertained by speech disorder, the criterion for inclusion in the Speech severity subgroup was a $z$ PCC-R score of -1 or lower relative to the reference data. Only 3 to 4 children in each hearing status group in Sample 2 met this criterion and, therefore, no Speech severity subgroups were assembled for Sample 2. In Sample 3, there were $13 \mathrm{OME}+$ and $9 \mathrm{OME}-$ children who met the criterion. In Sample 4, 48 of the 63 children had $z$ PCC-R scores at least 1 standard deviation below the mean of the reference data, possibly due to the lowered signal-noise ratios for the audiocassette recordings. Using the $20 \mathrm{~dB} \mathrm{HL}$ cut-off criterion for OME + and OME-, 12 of the OME + children and 36 of the OME - children had $z$ PCC-R scores below 1 standard deviation from the reference mean. As indicated above, there were no statistically significant differences in the gender or age composition of the Speech severity subgroups.

\section{Statistical analyses}

Distributional and other characteristics of the speech measures (e.g. skew and kurtosis, standard deviation ratios, correlations between means and standard deviations, percentage of $100 \%$ scores) have typically not met assumptions for parametric analyses, particularly for comparisons involving small cell sizes. Therefore, although means and standard deviations were used in the descriptive statistics displays, nonparametric Wilcoxon-Mann-Whitney inferential statistics (Siegel and Castellan, 1988) were completed for all between-group comparisons when measures were treated as continuous variables. When treated as a qualitative trait, differences in children's speech competence were tested using two-tailed Fisher exact tests. Given the theoretical and applied goals, it was considered equally important to avoid both Type I and Type II errors. Therefore, rather than using family-wise criteria to set significance levels (i.e. Bonferroni corrections), the decision was to acknowledge all obtained $p$ values at the 0.05 level or less as statistically significant. However, to be considered a candidate diagnostic marker, any statistically significant finding identified in Sample 1 (children with speech disorder) must have been replicated in at least one of the other three study samples (children unselected for speech disorder).

\section{Results}

\section{Speech and Intelligibility}

Sample 1

Table 2 is a summary of findings for Sample 1 (participants with Speech Delay) on the nine speech metrics and their subscales, including the Intelligibility Index. The 
Table 2. Summary of Sample 1 findings for the nine speech metrics

\begin{tabular}{|c|c|c|c|c|c|c|c|c|c|c|}
\hline & \multicolumn{10}{|c|}{ Sample 1} \\
\hline & \multicolumn{5}{|c|}{ Total group } & \multicolumn{5}{|c|}{ Speech severity subgroup } \\
\hline & \multicolumn{2}{|c|}{$\mathrm{OME}+(n=33)$} & \multicolumn{2}{|c|}{ OME $-(n=52)$} & \multirow[b]{2}{*}{$p$} & \multicolumn{2}{|c|}{$\mathrm{OME}+(n=12)$} & \multicolumn{2}{|c|}{ OME $-(n=27)$} & \multirow[b]{2}{*}{$p$} \\
\hline & $M$ & $S D$ & $M$ & $S D$ & & $M$ & $S D$ & $M$ & $S D$ & \\
\hline \multicolumn{11}{|l|}{$\mathrm{PCC}$} \\
\hline Early & 90.7 & 8.2 & 88.3 & 7.8 & 0.075 & 84.5 & 10.0 & 83.7 & 8.0 & 0.703 \\
\hline Middle & 73.5 & 15.2 & 66.6 & 15.1 & $0.042 *$ & 63.1 & 15.2 & 56.4 & 11.2 & 0.148 \\
\hline Late & 18.3 & 14.2 & 12.1 & 9.0 & 0.074 & 7.0 & 8.2 & 10.5 & 7.2 & 0.100 \\
\hline Total & 67.0 & 9.8 & 61.1 & 7.5 & $0.002 \dagger$ & 57.6 & 7.6 & 56.2 & 6.3 & 0.637 \\
\hline \multicolumn{11}{|l|}{ PCC-A } \\
\hline Middle & 73.7 & 15.1 & 66.7 & 15.2 & $0.037 *$ & 63.3 & 15.1 & 56.4 & 11.2 & 0.148 \\
\hline Late & 35.4 & 19.4 & 36.7 & 18.6 & 0.699 & 19.6 & 15.7 & 25.0 & 13.9 & 0.136 \\
\hline Total & 71.8 & 10.3 & 68.2 & 10.4 & 0.100 & 61.3 & 8.2 & 60.3 & 7.4 & 0.584 \\
\hline \multicolumn{11}{|l|}{ PCC-R } \\
\hline Early & 92.9 & 5.5 & 90.5 & 7.1 & 0.108 & 88.4 & 5.5 & 86.4 & 7.3 & 0.604 \\
\hline Middle & 76.8 & 14.3 & 70.8 & 14.7 & 0.068 & 66.8 & 14.6 & 61.4 & 12.3 & 0.229 \\
\hline Late & 38.5 & 19.5 & 40.6 & 18.9 & 0.586 & 21.2 & 15.8 & 28.9 & 14.6 & 0.068 \\
\hline Total & 74.4 & 9.6 & 71.5 & 9.6 & 0.154 & 64.6 & 7.2 & 64.1 & 6.8 & 0.626 \\
\hline \multicolumn{11}{|l|}{ PCI } \\
\hline Early & 99.2 & 3.1 & 97.9 & 6.0 & 0.277 & 97.8 & 5.0 & 96.2 & 7.9 & 0.636 \\
\hline Middle & 80.6 & 14.0 & 78.7 & 17.1 & 0.893 & 74.9 & 16.3 & 71.9 & 17.7 & 0.692 \\
\hline Late & 58.1 & 24.0 & 60.3 & 21.1 & 0.564 & 40.6 & 21.0 & 50.6 & 20.0 & 0.085 \\
\hline Total & 80.4 & 10.9 & 80.0 & 11.3 & 0.921 & 72.4 & 10.8 & 74.2 & 11.0 & 0.563 \\
\hline PVC & 91.4 & 4.6 & 91.0 & 4.1 & 0.606 & 89.4 & 6.3 & 90.2 & 4.6 & 1.000 \\
\hline PVC-R & 94.0 & 4.0 & 93.8 & 3.9 & 0.881 & 92.1 & 5.2 & 92.7 & 4.4 & 0.927 \\
\hline PPC & 77.0 & 6.6 & 73.2 & 5.0 & $0.003 \dagger$ & 70.7 & 5.6 & 70.1 & 4.5 & 0.625 \\
\hline PPC-R & 82.5 & 6.3 & 80.6 & 6.4 & 0.203 & 75.9 & 4.4 & 75.8 & 4.9 & 0.879 \\
\hline Int. Index & 84.6 & 15.1 & 92.6 & 6.7 & $0.019^{*}$ & 79.5 & 18.7 & 91.2 & 7.0 & 0.143 \\
\hline
\end{tabular}

$* p<0.05 ; \dagger p<0.01$.

Table 3. Summary statistical data for the Intelligibility-Speech Gap as a diagnostic marker for speech delay associated with otitis media with effusion ${ }^{b}$

\begin{tabular}{lcc}
\hline Metric & Obtained Value & $\begin{array}{c}\text { 95\% Confidence Interval for } \\
\text { the Classification Rule }\end{array}$ \\
\hline Positive Predictive Value & 0.74 & $0.60-0.89$ \\
Negative Predictive Value & 0.86 & $0.77-0.96$ \\
Sensitivity & 0.79 & $0.65-0.93$ \\
Specificity & 0.83 & $0.72-0.93$ \\
Diagnostic Accuracy & 0.81 & $0.73-0.90$ \\
Positive Likelihood Ratio & 4.6 & $2.5-8.5$ \\
Negative Likelihood Ratio & 0.25 & $0.13-0.50$ \\
\hline
\end{tabular}

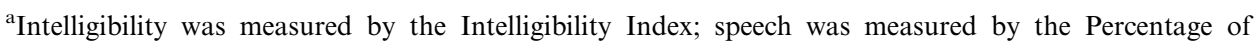
Consonants Correct (PCC) (Shriberg et al., 1997a).

${ }^{b}$ Classification Rule: $-0.02 \times($ Intelligibility Index-PCC) +0.91 . If the result is greater than 0.4313 , OME status $=\mathrm{OME}+$.

left columns, termed the Total group comparisons, include all children in each OME subgroup, and the right columns include data for the Speech severity subgroups.

For the Total group analyses, the 33 speech-disordered children with OME+ 
histories scored significantly higher than the 52 speech-disordered children with OME - histories on four of the following speech metrics: Percentage of Consonants Correct (PCC)-Middle-8 Consonants and Total Consonants, Percentage of Consonants Correct-Adjusted (PCC-A)-Middle- 8 Consonants and Percentage of Phonemes Correct (PPC)-Total Consonants. The PCC scores all consonant deletions, substitutions and distortions as incorrect, whereas the PCC-A scores five common clinical distortions as correct. The PPC scores all consonant and vowel/diphthong deletions, substitutions and distortions as incorrect (cf. Shriberg et al., 1997a). Although only a few of the comparisons were statistically significant, the children with speech disorder and OME + histories had higher scores than children with speech disorder and OME- histories on 16 of 19 (84.2\%) comparisons of the first eight speech measures and their subscales.

In contrast, the 33 children with speech disorder and OME + histories scored significantly lower $(p<0.019)$ than the 52 OME - speech-disordered children on the Intelligibility Index. Recall that the Intelligibility Index indicates the percentage of intelligible words in a conversational sample, that is, the percentage of intended words that the transcriber could gloss with some level of confidence. Children in the OME+ subgroup averaged 8 percentage points lower than OME- children on the Intelligibility Index. Note that the differences in standard deviations shown in table 2 were not a relevant concern for the inferential statistic, the nonparametric Wilcoxon-Mann-Whitney test. Thus, in the Total group, children with histories of $\mathrm{OME}+$ had significantly better articulation on four of the speech measures, but significantly poorer intelligibility. Using the PCC total consonants metric, the average difference or gap between intelligibility and PCC scores was considerably smaller for speech-delayed children with OME + histories (84.6\% [Intelligibility Index] - 67\% $[\mathrm{PCC}]=17.6 \%$ gap) compared to the gap for speech-delayed children with OMEhistories (92.6\% [Intelligibility Index $]-61.1 \%$ [PCC] $=31.5 \%$ gap). As shown in table 2 , trends were essentially similar for the Speech severity subgroup analyses (for the $\mathrm{OME}+$ children, the Intelligibility-Speech gap was $21.9 \%$; for the OME - children, the Intelligibility-Speech gap was $35 \%$ ), but none of the within-index comparisons was statistically significant.

\section{Samples 2-4}

Although the children in samples 2-4 were not ascertained as speech disordered, a question was whether intelligibility might be lower in OME + than in OMEchildren, even for children selected solely on the basis of their histories of OME. Figure 1 is a graphic summary of the comparisons for all four samples, including Total group $\mathrm{OME}+$ versus $\mathrm{OME}$ - comparisons, and where appropriate, OME severity subgroups and Speech severity subgroups. As indicated in figure 1, the trends for all 10 of the comparisons indicated that children with OME + histories had lower Intelligibility Index scores than children with OME - histories. A total of 6 of the 10 comparisons were statistically significant at the 0.05 level or higher. This pattern of significant differences indicated that lowered intelligibility in the OME+ subgroups was not found only in children with the most severe speech involvement or only in groups of children ascertained for speech disorder. Rather, statistically significant differences in intelligibility were obtained for the Total group 


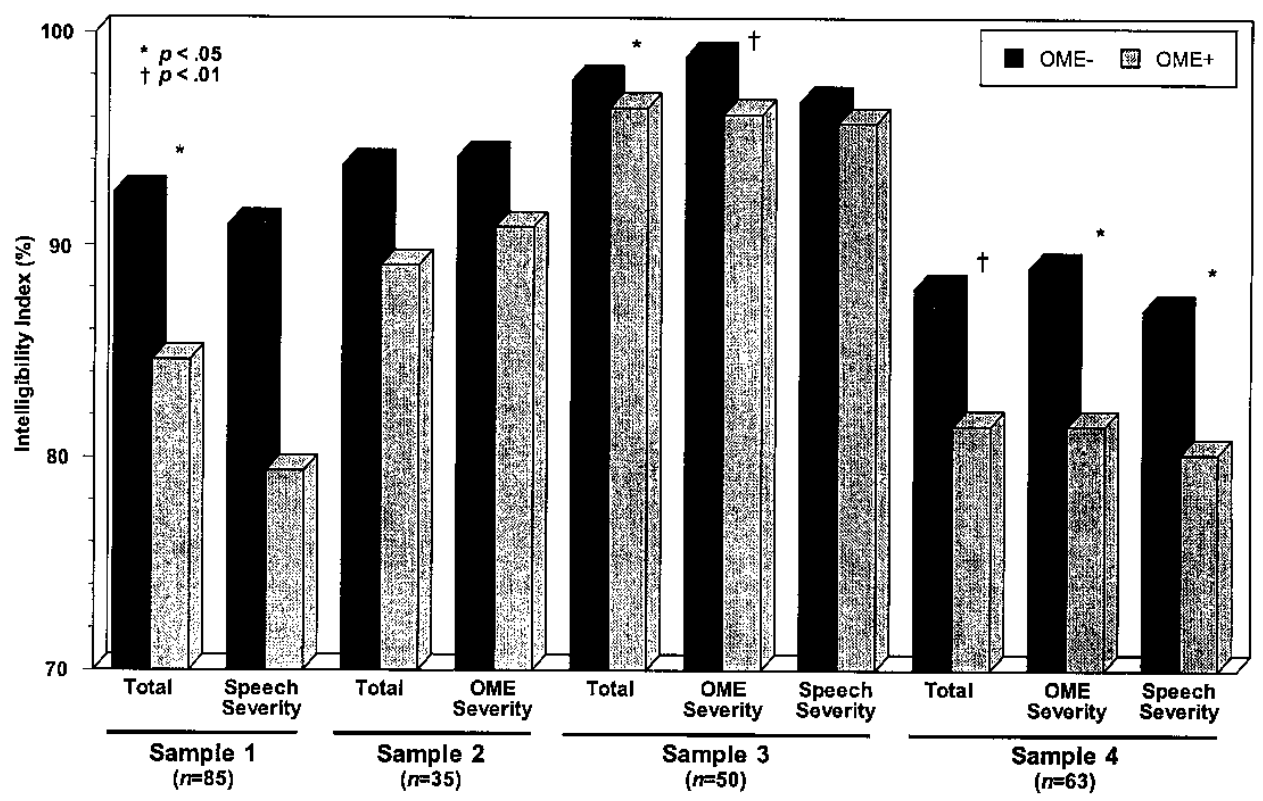

Figure 1. Intelligibility Index comparisons for children with positive $(O M E+)$ versus negative (OME-) histories of otitis media with effusion in four study samples.

comparisons in Sample 1, for Total group and OME severity comparisons in Sample 3, and for all three comparisons in Sample 4 (the youngest participants).

\section{Diagnostic marker analyses}

A series of diagnostic marker analyses was completed for the 85 children in Sample 1, the only one of the four samples that included children with SD as ascertained from a clinical population. The goal was to determine whether differences between a child's Intelligibility Index and any of the speech scores might have potential as a diagnostic marker for SD-OME. The analyses included logistic regression and machine learning techniques (PolyAnalyst 3.0) to differentiate the two groups on the clinical validity measures. One analysis in each series used difference scores between the two domains, which retained the absolute magnitudes of differences. A second analysis converted differences to ratios, effectively standardizing for the absolute differences in percentages. In view of the many uncontrolled methodological issues in these retrospectively assembled data, a minimum of $75 \%$ accuracy was selected as a promising criterion level for analysis results on the first measurement criteria reviewed at the outset of this paper: positive and negative predictive values and sensitivity and specificity (also the average of sensitivity and specificity, termed diagnostic accuracy). Specificity findings were limited to the comparison between $\mathrm{OME}+$ and OME - histories, as none of the other etiological subtypes of speech disorder of currently unknown origin included in the Speech Disorders Classification System (Shriberg et al., 1997b) were differentiated in Sample 1. We were also interested in the positive and negative 
likelihood ratios associated with a marker, but no minimal criteria for diagnostic accuracy were set.

Table 3 is a summary of the findings from these analyses. As noted in the group findings, a diagnostic marker termed the Intelligibility-Speech Gap (hereafter, the I-S gap) yielded the best discrimination on the five clinical metrics and best positive and negative likelihood ratios. Discrimination accuracy values ranged from $74 \%$ to $86 \%$, with the expectedly wide confidence intervals for the logistic regression likely associated with the relatively small cell sizes in this study. The prediction rule accurately identified 27 of the $33 \mathrm{OME}+$ cases (sensitivity) and 43 of the $52 \mathrm{OME}-$ cases (specificity). If used as a diagnostic marker, the I-S gap would have correctly predicted OME status for 26 of the 35 positive I-S gap results (positive predictive value) and 43 of the 50 negative I-S gap results (negative predictive value). As indicated by the likelihood ratios, a positive score on the I-S gap marker is 4.6 times as likely to be obtained by a child with SD and an OME + history than by a child with SD and an OME - history. Finally, as shown in table 3, a child with SD whose I-S gap falls into the negative marker range is less than three-tenths as likely to have an $\mathrm{OME}+$ history than an OME- history.

\section{Discussion}

Some methodological constraints on the present findings are important to consider before proceeding to a discussion of the group and diagnostic accuracy findings for the Intelligibility-Speech gap.

\section{Method issues}

Phonetic transcription and recording media

A possible methodological explanation for the higher speech production scores but lowered intelligibility observed in children with suspected SD-OME is that auditory-perceptual speech data (i.e. transcripts from narrow phonetic transcription) are not sufficiently sensitive to the acoustic correlates of reduced intelligibility. That is, transcription may underestimate those speech behaviours associated with OME that attenuate intelligibility. Although broad phonetic transcription has adequate to excellent point-to-point agreement (80\%-90\%), narrow phonetic transcription may not have the sensitivity or reliability $(60 \%-70 \%)$ needed for analysis of minimal sound changes (Shriberg and Lof, 1991; McSweeny and Shriberg, 1995).

In a discussion of validity and reliability problems in phonetic transcription, Cucchiarini (1996) has noted that the fundamental problem is that transcription forces a nominal classification (i.e. diacritic symbolization) of events that are inherently continuous (see also Kent, 1996; Connolly, 1997). Acoustic analyses, which do provide continuous values on speech variables, may be needed for parametric descriptions of speech in OME, much as acoustic differences associated with intelligibility have been widely studied in persons with deficits in speech motor control (e.g. Ziegler and Hartmann, 1996; Weismer, 1997).

Studies currently in process indicate that the recording media and transcript analysis procedures used in studies of child speech-sound disorders are sources of potential variance requiring controlled study. As has occurred in the study of other communicative disorders, a shift to digital recording and transcription aided by 
acoustic analysis may eventually provide sensitive and reliable data at subphonemic levels of transcription of disordered speech. It could be that the I-S gap observed in the present data might narrow further when the speech patterns associated with OME histories are captured and quantified using digital technologies.

\section{Hearing levels}

A second possible methodological constraint concerns the absence of hearing level information in three of the four study samples. The goal of the present study was to address a public health question from the perspective of typical information available in a clinical context, which may at best include one or a few audiological screenings or threshold assessments. Accordingly, the information on children's hearing, in particular, is subject to the many forms of data reporting bias that have been reported in the literature. It is not clear how the availability of such information would impact the present findings. One possibility is that the accuracy level of the diagnostic marker would have been slightly to markedly higher if the study had used more strict inclusionary criteria including audiological documentation of frequent and significant levels of hearing loss. Alternatively, hearing information and other subject variables not accounted for in the present sample could limit generalizations from the present data. Clearly, larger and more diverse samples need to be studied to provide a better estimate of the generalizability of the present findings for clinical use, including estimates of the confidence levels around the I-S gap as a diagnostic marker for SD-OME.

\section{Classification and normalization}

It is important to note that the origins of speech delay in the OME- or control group in this study were unknown. The diagnostic marker described here for SDOME might have greater or less specificity given comparison groups in which children have well defined etiological subtypes of speech delay. For example, in a study that used procedures similar to those used in Sample 1 to select children from a clinical archive, $56 \%$ of the speech-disordered children had one or more family members who had or used to have the same speech problem (Shriberg and Kwiatkowski, 1994). Such familial aggregation findings are generally used to support the hypothesis of a genetically transmitted subtype of speech delay.

The familial aggregation findings described above raise the question of possible genetic influences on the intelligibility and PCC scores obtained in the present data. If the source of disorder for many of the children in the OME- groups was indeed genetic transmission, it would suggest that such etiological origins have less severe consequences for intelligibility (but worse for speech) compared to SD-OME. The two possible origins are not mutually exclusive, of course, with the co-occurrence of both estimated in part by their independent incidence and prevalence rates (cf. Shriberg and Austin, 1998; Shriberg et al., 1999). To a first approximation, the unconditional probability of $56 \%$ of children with familial aggregation in Shriberg and Kwiatkowski (1994) (i.e. with familial aggregation a plausible interim proxy for genetic etiology) would predict that over half of the children with $\mathrm{OME}+$ may also have had SD associated with genetic transmission. It would follow that such possibly additive risk factors would be reflected in more severe involvement. Additional research confounds include likely differences in normalization rates for 
different subtypes of speech disorder (cf. Lonigan, Fischel, Whitehurst, Arnold and Valdez-Menchaca, 1992; Shriberg, Gruber and Kwiatkowski, 1994).

The points underscored here represent only some of the complex of variables that could affect the accuracy of a proposed diagnostic marker for SD-OME. There is currently no way to calculate the effects of such possible confounds on the generalizability of the diagnostic accuracy values reported for the present proposed diagnostic marker.

\section{Direct versus mediated accounts of the effects of OME on speech acquisition}

What are the implications of findings on intelligibility and speech for alternative pathway accounts of OME as a risk factor for speech delay? Both the findings for lowered intelligibility and higher speech accuracy in children with SD and OME+ compared to $\mathrm{OME}$ - histories warrant analytic consideration. On balance, we view both findings as providing more support for the mediated account.

A methodological issue is whether there is a complementary relationship between speech scores and intelligibility scores. Because unintelligible words are excluded from the pool of words from which speech metrics like the PCC are calculated, there is the possibility that the PCCs of highly unintelligible children can be artificially high. This relationship could be suspected in the present findings of a reduced I-S gap for the children with $\mathrm{SD}$ and $\mathrm{OME}+$ histories (i.e. lower intelligibility scores and higher speech scores). If the relationship between the two measures was reasonably linear and monotonic, the expectation would be that the two measures are significantly negatively correlated in groups of children whose speech delays represent the full range of severity of impairment. In fact, however, correlations between the two measures are extremely stable across samples, consistently averaging only in the low 0.40 s (less than $20 \%$ common variance) in different studies (e.g. Bishop and Edmundson, 1986; see review in Weston and Shriberg, 1992). Thus, the Intelligibility Index and the Percentage of Consonants Correct metrics have at least $80 \%$ non-shared variance. This suggests that factors other than the articulatory precision of speech are involved when words are unintelligible to both examiners online and transcribers allowed at least three replays to attempt to gloss each word. Even if the speech errors in SD-OME were less precise and more unusual than those observed in children without OME+ histories, they would presumably be sufficiently stable to allow examiners and transcribers to make the translations needed to gloss words that involved unusual but predictable speech errors.

In associated studies we have explored alternative correlates of reduced intelligibility in children with speech delay of unknown origin (cf. Weston and Shriberg, 1992). As with models of intelligibility deficits in other communicative disorders, contributions to intelligibility appear to obtain from a variety of variables within cognitive, language, prosodic and motivational domains, in addition to the contributions from segmental variables (such as those reviewed previously as potential diagnostic markers of SD-OME). A review of relevant literatures on alternative models of intelligibility is beyond the scope of the present focus. Essentially, we interpret the lowered intelligibility component of the reduced I-S gap as support for the mediated as opposed to the direct effects causal model of SD-OME. 
Speculation on which of the two accounts provides a more parsimonious explanation for the elevated speech component of the I-S gap in children with suspected SD and OME + histories is challenging. Support for both accounts can be marshalled. The direct effects model predicts that the speech errors associated with SD-OME are circumscribed to those that depend on salient perceptual cues. Thus, in comparison to the more widespread errors associated with the cognitive and articulatory constraints proposed for other etiological subtypes of SD (e.g. those proposed to be genetically transmitted or associated with motor-speech impairment), children with SD-OME might be expected to have higher PCC scores. However, there may be a developmental cascade effect such that unstable representations of the earliest emerging sounds (e.g. nasals and stops; see Shriberg et al., 2003) mediate emergence of later speech sounds. Thus, although the acquisition of stable representations for only certain sounds is directly affected by the intensity-frequency deficits that define the audiometric profiles of OME-based hearing loss, the effect of perturbation at the earliest stages of comprehension phonology may be widespread speech delay. This mediated account would thus explain the present findings that children with suspected SD-OME have the common sound changes that define speech delay (e.g. final consonant deletion, cluster reduction, stopping, etc.), but have less extensive involvement - as indicated by their higher scores on measures such as the PCC (see table 2). On balance, therefore, the speech findings in SD-OME - including those in both the early speech studies reviewed previously and in the present study - appear to fit the mediated better than the direct effects model.

\section{Conclusion}

The findings of this study suggest that a diagnostic marker of speech delay associated with early recurrent otitis media with effusion may be available in a metric reflecting the width of a gap between a child's intelligibility and his or her consonant accuracy in a conversational speech sample. This gap was smaller in children with speech delay and OME + histories compared to children with speech delay and OME - histories.

The magnitudes of the positive (4.6) and negative (0.25) likelihood ratios obtained in the present study are particularly encouraging, as this information may eventually be most useful for clinical decision making in speech delay of unknown origin. If the present findings are supported in cross-validation studies, such information could be used by speech-language pathologists to provide additional assessment of perceptually related domains and processes for children with small I-S gaps. For the present, these findings should be viewed cautiously, perhaps providing support for clinicians pressed for time to adequately assess each child's individual case history. If SD-OME is eventually validated as one of several etiological subtypes of speech delay, it will likely benefit from treatment approaches tailored to the perceptually based deficits in speech production. Good progress on the identification of such processes in infants and toddlers with OME has been made in the research on proximal psycholinguistic variables reviewed previously. Continued inquiry into the source and nature of both distal and proximal causal sources should yield information for treatment and eventual prevention of the communicative challenges faced by some children with early significant ear disease. 


\section{Acknowledgements}

Preparation of this report was supported by the National Institute on Deafness and Other Communication Disorders, National Institutes of Health (DC00496). We extend sincere thanks to the following colleagues for their significant contributions to this study: Chad Allen, Diane Austin, Sheryl Hall, Katherina Hauner, Ray Kent, Connie Nadler, Sandi Friel-Patti, Carmen Rasmussen, Dorothy Rorick Ross, Alison Scheer, Jennine Sprangers, Helen Thielke, Carol Widder, David Wilson and Marie Wirka. The authors dedicate this work to the memory of Dr. Sandy FrielPatti, a wonderful colleague and friend whose many outstanding contributions to this discipline and personal courage continue to inspire all who were privileged to know her.

\section{References}

Bennett, K. E. and Haggard, M. P., 1999, Behaviour and cognitive outcomes from middle ear disease. Archives of Disease in Childhood, 80, 28-35.

Bird, J., Bishop, D. V. M. and Freeman, N. H., 1995, Phonological awareness and literacy development in children with expressive phonological impairments. Journal of Speech and Hearing Research, 38, 446-462.

Bishop, D. V. M. and Edmundson, A., 1986, Is otitis media a major cause of specific developmental language disorders? British Journal of Disorders of Communication, 21, 321-338.

CAsby, M. W., 2001, Otitis media and language development: a meta analysis. American Journal of Speech-Language Pathology, 10, 65-80.

ConNolly, J. H., 1997, Quantifying target-realization differences: part I: segments. Clinical Linguistics and Phonetics, 11, 267-287.

CuCChIARINI, C., 1996, Assessing transcription agreement: methodological aspects. Clinical Linguistics and Phonetics, 10, 131-155.

Feldman, H. M., Dollaghan, C. A., Campbell, T. F., Colborn, D. K., Kurs-Lasky, M., JANOSKY, J. E. and PARADISE, J. L., 1999, Parent-reported language and communication skills at one and two years of age in relation to otitis media in the first two years of life. Pediatrics, 104, e52.

Felsenfeld, S., Broen, P. A. and McGue, M., 1992, A 28-year follow-up of adults with a history of moderate phonological disorder: linguistic and personality results. Journal of Speech and Hearing Research, 35, 1114-1125.

Friel-PatTi, S. and Finitzo, T., 1990, Language learning in a prospective study of otitis media with effusion in the first two years of life. Journal of Speech and Hearing Research, 33, 188-194.

Holm, V. A. and Kunze, L. H., 1969, Effect of chronic otitis media on language and speech development. Pediatrics, 43, 833-839.

Howell, P. and BonnetT, C., 1997, Speaking clearly for the hearing impaired: intelligibility differences between clear and less clear speakers. European Journal of Disorders of Communication, 32, 89-97.

KENT, R. D., 1996, Hearing and believing: some limits to the auditory-perceptual assessment of speech and voice disorders. American Journal of Speech-Language Pathology, 5, 7 23.

KINDIG, J. S. and RichaRDS, H. C., 2000, Otitis media: precursor of delayed reading. Journal of Pediatric Psychology, 25, 15-18.

Klausen, O., Møller, P., Holmefjord, A., Reisæter, S. and Asbjørnsen, A., 2000, Lasting effects of otitis media with effusion on language skills and listening performance. Acta Otolaryngol, Supp., 543, 73-76.

Krause, J. C. and BraidA, L. D., 1995, The effects of speaking rate on the intelligibility of speech for various speaking modes. Journal of the Acoustical Society of America, $\mathbf{9 8 ,}$ 2982.

Levitt, H. and Stromberg, H., 1983, Segmental characteristics of the speech of 
hearing-impaired children: factors affecting intelligibility. In I. Hochberg, H. Levitt and M. J. Osberger (Eds), Speech of the Hearing Impaired (Baltimore, MD: University Park Press), pp. 53-74.

Lindsay, R. L., Tomazic, T., Whitman, B. Y. and Accardo, P. J., 1999, Early ear problems and developmental problems at school age. Clinical Pediatrics, 38, 123-132.

Lonigan, C. J., Fischel, J. E., Whitehurst, G. J., Arnold, D. S. and Valdez-Menchaca, M. C., 1992, The role of otitis media in the development of expressive language disorder. Developmental Psychology, 28, 430-440.

Maw, R., Wilks, J., Harvey, I., Peters, T. J. and Golding, J., 1999, Early surgery compared with watchful waiting for glue ear and effect on language development in preschool children: a randomized trial. The Lancet, 353, 960-963.

McSweeny, J. L. and Shriberg, L. D., 1995, Segmental and suprasegmental transcription reliability, Tech. Rep. No.2 (Phonology Project, Waisman Center, University of Wisconsin-Madison).

Miccio, A. W., Gallagher, E., Grossman, C. B., Yont, K. M. and Vernon-Feagans, L., 2001, Influence of chronic otitis media on phonological acquisition. Clinical Linguistics and Phonetics, 15, 47-51.

Miccio, A. W., Yont, K. M., Davie, J. and Vernon-Feagans, L., 1999, Continuity in the acquisition of consonants by toddlers with chronic otitis media. In J. J. Ohala, H. Hasegawa, M. Ohala, D. Granville and A. C. Bailey (Eds) Proceedings of the $14^{\text {th }}$ International Conference of Phonetic Sciences, 1 (Berkeley, CA: University of California Linguistics), pp. 827-830.

Miller, J. F. and Chapman, R., 1986, Systematic Analysis of Language Transcripts (SALT) [Computer software] (Madison, WI: Waisman Center, University of Wisconsin).

Mody, M. and Schwartz, R. G., 1999, Speech perception and verbal memory in children with and without histories of otitis media. Journal of Speech, Language, and Hearing Research, 42, 1069-1079.

OSBerger, M. J., 1992, Speech intelligibility in the hearing impaired: research and clinical implications. In R. D. Kent (Ed.), Intelligibility in Speech Disorders: Theory, measurement, and management (Amsterdam: John Benjamins), pp. 231-264.

Paradise, J. L., Dollaghan, C. A., Campbell, T. F., Feldman, H. M., Bernard, B. S., Colborn, D. K., Rockette, H. E., Janosky, J. E., Pitcairn, D. L., Sabo, D. L., Kurs-LASKy, M. and Smith, C. G., 2000, Language, speech sound production, and cognition in three-year-old children in relation to otitis media in their first three years of life. Pediatrics, 105, 1119-1130.

Paradise, J. L., Feldman, H. M., Campbell, T. F., Dollaghan, C. A., Colborn, D. K., Bernard, B. S., Rockette, H. E., Janosky, J. E., Pitcairn, D. L., Sabo, D. L., Kurs-Lasky, M. and Smith, C. G., 2001, Effect of early or delayed insertion of tympanostomy tubes for persistent otitis media on developmental outcomes at the age of three years. New England Journal of Medicine, 344, 1179-1187.

Paul, R., 1995, Language Disorders: Infancy through Adolescence: Assessment and intervention (St. Louis, MO: Mosby).

Petinou, K. C., Schwartz, R. G., Gravel, J. S. and Raphael, L. J., 2001, A preliminary account of phonological and morphophonological perception in young children with and without otitis media. International Journal of Language and Communication Disorders, 36, 21-42.

Petinou, K. C., Schwartz, R. G., Mody, M. and Gravel, J. S., 1999, The impact of otitis media with effusion on early phonetic inventories: a longitudinal prospective investigation. Clinical Linguistics and Phonetics, 13, 351-367.

Picheny, M. A., Durlach, N. I. and Braida, L. D., 1986, Speaking clearly for the hard of hearing II: acoustic characteristics of clear and conversational speech. Journal of Speech and Hearing Research, 29, 434-446.

Picheny, M. A., Durlach, N. I. and Braida, L. D., 1989, Speaking clearly for the hard of hearing III: an attempt to determine the contribution of speaking rate to difference in intelligibility between clear and conversational speech. Journal of Speech and Hearing Research, 32, 600-603.

PolyAnalyst 3.0., 1997, Megaputer Intelligence Inc., Bloomington, IN.

Roberts, J. E., Burchinal, M. R., Jackson, S. C., Hooper, S. R., Roush, J., Mundy, M., 
Neebe, E. C. and Zeisel, S. A., 2000, Otitis media in early childhood in relation to preschool language and school readiness skills among black children. Pediatrics, 106, 725-735.

Roberts, J. E., Burchinal, M. R., Zeisel, S. A., Neebe, E. C., Hooper, S. R., Roush, J., Bryant, D., Mundy, M. and Henderson, F. W., 1998, Otitis media, the caregiving environment, and language and cognitive outcomes at two years. Pediatrics, 102, $346-354$.

Roberts, J. and Hunter, L. (Chairs)., 2002, Otitis media and language learning sequelae: current research and controversies. Symposium conducted in Arlington, Virginia, May.

Rosenfeld, R. M., Bhaya, M. H., Bower, C. M., Brookhouser, P. E., Casselbrant, M. L., Chan, K. H., Cunningham, M. J., Derkay, C. S., Gray, S. D., Manning, S. C., Messner, A. H. and Smith, R. J. H., 2000, Impact of typanostomy tubes on child quality of life. Archives Otolaryngology-Head and Neck Surgery, 126, 585-592.

Rvachew, S., Slawinski, E. B., Williams, M. and Green, C. L., 1996a, Formant frequencies of vowels produced by infants with and without early onset otitis media. Canadian Acoustics, 24, 19-28.

Rvachew, S., Slawinski, E. B., Williams, M. and Green, C. L., 1996b, The impact of early onset otitis media on prelinguistic speech development. Journal of SpeechLanguage Pathology and Audiology, 20, 247-255.

Rvachew, S., Slawinski, E. B., Williams, M. and Green, C. L., 1999, The impact of early onset otitis media on babbling and early language development. Journal of the Acoustical Society of America, 105, 467-475.

Sackett, D. L., Haynes, R. B., Guyatt, G. H. and Tugwell, P., 1991, Clinical Epidemiology: A basic science for clinical medicine, second edition (Boston, MA: Little, Brown \& Company).

SHRIBERG, L. D., 1987, In search of the otitis media-speech connection. Journal of the National Student Speech Language Hearing Association, 15, 56-67.

ShriberG, L. D., 1993, Four new speech and prosody-voice measures for genetics research and other studies in developmental phonological disorders. Journal of Speech and Hearing Research, 36, 105-140.

Shriberg, L. D., Allen, C. T., McSweeny, J. L. and Wilson, D. L., 2001, PePPer: Programs to examine phonetic and phonologic evaluation records [Computer software] (Madison, WI: Waisman Center, University of Wisconsin).

ShriberG, L. D. and Austin, D., 1998, Comorbidity of speech-language disorder: implications for a phenotype marker for speech delay. In R. Paul (Ed.), The Speech/Language Connection (Baltimore, MD: Paul H. Brookes).

Shriberg, L. D., Austin, D., Lewis, B. A., McSweeny, J. L. and Wilson, D. L., 1997a, The Percentage of Consonants Correct (PCC) metric: extensions and reliability data. Journal of Speech and Hearing Research, 40, 708-722.

Shriberg, L. D., Austin, D., Lewis, B. A., McSweeny, J. L. and Wilson, D. L., 1997b, The Speech Disorders Classification System (SDCS): extensions and lifespan reference data. Journal of Speech and Hearing Research, 40, 723-740.

Shriberg, L. D., Flipsen, P., Jr., Thielke, H., Kwiatkowski, J., Kertoy, M., Katcher, M., Nellis, R. and BLOCK, M., 2000, Risk for speech disorder associated with early recurrent otitis media with effusion: two retrospective studies. Journal of Speech, Language, and Hearing Research, 43, 79-99.

Shriberg, L. D., Friel-Patti, S., Flipsen, P., JR. and Brown, R. L., 2000, Otitis media, fluctuant hearing loss, and speech-language outcomes: a preliminary structural equation model. Journal of Speech, Language, and Hearing Research, 43, 100120.

Shriberg, L. D., Gruber, F. A. and Kwiatkowski, J., 1994, Developmental phonological disorders III: long-term speech-sound normalization. Journal of Speech and Hearing Research, 37, 1151-1177.

Shriberg, L. D. and Kent, R. D., 1995, Clinical Phonetics, second edition (Boston, MA: Allyn \& Bacon).

Shriberg, L. D., Kent, R. D., Karlsson, H. B., McSweeny, J. L., Nadler, C. J. and Brown, R. L., 2003, A diagnostic marker for speech delay associated with otitis 
media with effusion: backing of obstruents. Clinical Linguistics and Phonetics, 17, $529-547$.

Shriberg, L. D. and Kwiatkowski, J., 1980, Natural Process Analysis: A procedure for phonological analysis of continuous speech samples (New York: Macmillan).

ShriberG, L. D. and KwiATKOWSKI, J., 1990, Self-monitoring and generalization in preschool speech-delayed children. Language, Speech, and Hearing Services in Schools, 21, 157-170.

Shriberg, L. D. and Kwiatkowski, J., 1994, Developmental phonological disorders I: a clinical profile. Journal of Speech and Hearing Research, 37, 1100-1126.

ShriberG, L. D. and Lof, G. L., 1991, Reliability studies in broad and narrow phonetic transcription. Clinical Linguistics and Phonetics, 5, 225-279.

Shriberg, L. D. and Smith, A. J., 1983, Phonological correlates of middle-ear involvement in speech-delayed children: a methodological note. Journal of Speech and Hearing Research, 26, 293-297.

Shriberg, L. D., Tomblin, J. B. and McSweeny, J. L., 1999, Prevalence of speech delay in 6-year-old children and comorbidity with language impairment. Journal of Speech, Language, and Hearing Research, 42, 1461-1481.

Siegel, S. and Castellan, N. J., JR., 1988, Nonparametric Statistics for the Behavioral Sciences, second edition (New York: McGraw-Hill).

Silverman, F. H. and Paulus, P. G., 1989, Peer reactions to teenagers who substitute /w/ for /r/. Language, Speech, and Hearing Services in Schools, 20, 219-221.

Stoel-Gammon, C. and Kehoe, M., 1994, Hearing impairment in infants and toddlers: identification, vocal development, and intervention in child phonology. In J. Bernthal and N. Bankson (Eds), Child Phonology: Characteristics, assessment, and intervention with special populations (New York: Thieme Medical Publishers), pp. 163-181.

Weismer, G., 1997, Motor speech disorders. In W. J. Hardcastle and J. Laver (Eds), The Handbook of Phonetic Sciences (Cambridge, MA: Blackwell), pp.191-219.

Weston, A. D. and Shriberg, L. D., 1992, Contextual and linguistic correlates of intelligibility in children with developmental phonological disorders. Journal of Speech and Hearing Research, 35, 1316-1332.

Ziegler, W. and Hartmann, E., 1996, Perceptual and acoustic methods in the evaluation of dysarthric speech. In M. J. Ball and M. Duckworth (Eds), Advances in Clinical Phonetics (Amsterdam: John Benjamins), pp.91-114. 
Copyright $\odot 2003$ EBSCO Publishing 